\title{
Prevalence of Anemia in Patients with COPD and Its Potential Impact on Morbidity of COPD Patients
}

\author{
Shaheena Parveen1, Imran Rangreze ${ }^{2 *}$, Syed Nisar Ahmad ${ }^{3}$, Showkat Ali Mufti, \\ Shehla Shafi Khan 5 \\ ${ }^{1}$ Departmrnt of Gastroenterology, Sher-i-Kashmir Institute of Medical Sciences, Soura, India \\ ${ }^{2}$ Department of Medicine, King Khalid University, Abha, KSA \\ ${ }^{3}$ Departmrent of Medical Oncology, Sher-i-Kashmir Institute of Medical Sciences, Soura, India \\ ${ }^{4}$ Department of Medicine, Sher-i-Kashmir Institute of Medical Sciences, Soura, India \\ ${ }^{5}$ Armed Force Hospital, Southern Region, Khamis Mushayt, KSA \\ Email: ${ }^{*}$ dr.imranr@gmail.com
}

Received 28 February 2014; revised 27 March 2014; accepted 8 April 2014

Copyright (C) 2014 by authors and Scientific Research Publishing Inc.

This work is licensed under the Creative Commons Attribution International License (CC BY).

http://creativecommons.org/licenses/by/4.0/

(c) (i) Open Access

\section{Abstract}

Background: Although COPD is traditionally associated with polycythemia, the systemic inflammation that is now recognized as a feature of COPD makes it a possible cause of Anemia of Chronic Disease (ACD). Preliminary evidences suggest that anemia in COPD may be more prevalent than expected occurring in $10 \%-15 \%$ of patients. While in states like chronic heart failure and renal insufficiency, anemia has been extensively studied; little attention has been given to it in COPD. Objectives: To see the prevalence of anemia in patients with COPD and its potential impact on morbidity of COPD patients. Design and Setting: A university hospital-based cross-sectional study in Kashmir, India. Methods: Two hundred patients (119 males and 81 females) with spirometery documented COPD were evaluated for frequency of anemia. In addition to routine investigations, erythropoietin levels were done in a subgroup of patients. Results: A total of 36 cases $(20$ males and 16 females) of anemia were detected giving a frequency of $18 \%$. Normocytic normochromic type of anemia was present in $32(88.89 \%)$ patients while the rest had normocytic hypochromic type of anemia. Majority of patients were in GOLD stage 11 and had decreased serum iron, transferrin saturation and TIBC. Erythropoietin levels were significantly raised in anemic COPD patients compared to non-anemic COPD patients. The various factors significantly associated with anemia were: No. of exacerbations of COPD, No. of hospital admissions, BMI and erythropoietin levels. Conclusion: Anemia occurs frequently in patients of COPD and is associated with increased morbidity in the form of No. of exacerbations and hospital admissions. Correcting anemia in these patients may improve their clinical outcome.

\footnotetext{
*Corresponding author. Imran Rangreze: Assistant Professor, King Khalid University, Abha, KSA.
} 


\section{Keywords}

\section{COPD, Anemia}

\section{Introduction}

Many chronic diseases have been shown to affect haematopoiesis, resulting in shortening of red blood cell (RBC) lifespan and sequestration of iron in macrophages, and leading to so-called anemia of chronic disease (ACD) [1]. Over the past years, the clinical scope of this syndrome has stretched beyond its traditional chronic infectious, inflammatory and neoplastic causes, to include heart failure [2] [3]. Theoretically, chronic obstructive pulmonary disease (COPD) is another candidate likely to be associated with ACD, when considered in relation to already-known systemic effects of the disease [4].

The anemia found in patients with chronic infectious, inflammatory and neoplastic disorders, known as ACD, is one of the most common syndromes in medicine. A characteristic finding of the disorders associated with ACD is increased production of cytokines that mediate the immune or inflammatory response, such as tumor necrosis factor, interleukin-1 and the interferons. All the processes involved in the development of ACD can be attributed to these cytokines, including shortened red cell survival, blunted erythropoietin response to anemia, impaired erythroid colony formation in response to erythropoietin and abnormal mobilization of reticuloendothelial iron stores [5].

Recent GOLD report [6] [7] has changed the characteristics of COPD staging. In the 2006 GOLD report, more emphasis is given to the role of inflammation in COPD.

Anemia of chronic illness is typically normocytic anemia and is most commonly observed in patients with concurrent infectious, inflammatory or neoplastic diseases. COPD fulfills the criteria of a chronic, inflammatory multisystem disease leading to expectations of anemia and the mechanism of anemia development might be similar to that in other chronic diseases. Anemia is such a common and simple finding that we may underestimate its physiologic relevance in COPD [8] [9].

Mathias John et al. [9] in a group of 101 COPD patients found that anemia occurred frequently in COPD patients $(13 \%)$ and is related to the presence of inflammation. Furthermore, anemic COPD patients showed increased levels of erythropoietin compared to non-anemic and normal subjects which may indicate the presence of erythropoietin resistance. The latter may be mediated through inflammatory mechanisms, which is typical anemia of chronic illness. Anemia appeared normocytic and normochromic.

In a prospective study, C. Cote et al. found that anemia was present in $17 \%$ and polycythemia in $6 \%$ of COPD patients. Anemia in COPD was an independent risk factor for reduced functional capacity. Polycythemia prevalence was low and had no association with poor outcome [10].

Although COPD is traditionally associated with polycythemia, the systemic inflammation that is now recognized as a feature of COPD makes it a possible cause of ACD. If present in COPD, anemia could worsen dyspnoea and limit exercise tolerance [11].

Preliminary evidence suggests that anemia in COPD patients may be more prevalent than expected, occurring in $10 \%-15 \%$ of patients suffering from severe forms of the disease. A database study conducted in 2524 COPD patients being prescribed long-term oxygen therapy has shown that a low hematocrit is a strong predictor of survival in this population, before body mass index and is associated with more hospitalizations and a longer cumulative duration of hospitalization. COPD patients with low hemoglobin levels have a poorer prognosis than COPD patients with normal hemoglobin levels in the event of acute gastrointestinal bleeding or after elective aneurysm repair. Raising hemoglobinemia through transfusion decreases minute ventilation and work of breathing in COPD patients [11].

Berned Schonhofer et al. in their study found that red blood cell transfusion in anemic patients with COPD leads to a significant reduction of both the minute ventilation and the work of breathing. In these patients, transfusion may be associated with unloading of respiratory muscles, but it may also result in mild hypoventilation [12].

These preliminary evidences point to the need to study the prevalence of anemia and its physiological and clinical impact in COPD. When this body of knowledge is available, the question of putative benefits of raising 
hemoglobinemia in chronic obstructive pulmonary disease will have to be addressed [11] [12].

Our study is directed towards the prevalence of anemia in the COPD patients and clinical characteristics associated with these patients in the form of No. of exacerbations and hospital admissions.

Correcting anemia in these patients may improve their clinical outcome.

\section{Material and Methods}

We studied 200 consecutive patients with COPD after obtaining informed consent from them. The patients were enrolled from both outpatient and inpatient (wards) departments of the hospital. The study was approved by the ethical committee that looks into the ethical aspects of the human experimentation.

Inclusion criteria:

The patients included in the study were men and women (both smokers and non-smokers) aged 40 years or more with history suggestive of COPD (cough with sputum production in chronic bronchitis and breathlessness in emphysema), physical findings suggestive of airway obstruction (rhonchi, decreased intensity of breath sounds and prolonged expiration) and importantly a spirometery confirmed diagnosis of COPD as per GOLD criteria [6]; only those patients who had a FEV1/FVC ratio of less than $70 \%$ were included in the study.

Anemia was defined by hemoglobin level $<13.5 \mathrm{gm} / \mathrm{dl}$ in male patients and $<12 \mathrm{gm} / \mathrm{dl}$ in female patients [9].

Exclusion criteria:

1) All patients with insufficient mental capacity that precluded obtaining an informed consent from them.

2) Current or past diagnosis of asthma.

3) Patients with cancer, thyroid disease, severe liver disease, chronic kidney disease, chronic heart failure, rheumatoid arthritis, G I haemorhage or blood loss of any other cause and patients with a known vitamin B12 or folic acid deficiency were not enrolled.

A detailed history and examination were performed as per proforma.

These patients were subjected to following investigations.

a) Lung function tests (spirometery) which was done by S-model spirometer (vitalograph limited medical instrumentation made in United Kingdom). Mean of three readings was taken. Predicted FEV1 was calculated from Indian norms for pulmonary functions.

b) Hemogram: -Hb, Hct, MCV, MCH, and MCHC.

c) Peripheral blood film (PBF).

d) Liver function tests.

e) Renal function tests.

f) Arterial blood gas (ABG)- $\mathrm{PaO}_{2}, \mathrm{SaO}_{2}, \mathrm{PaCO}_{2}, \mathrm{HCO}_{3}, \mathrm{pH}$.

g) Chest X-Ray.

h) Iron Profile: -Serum iron, Transferrin saturation, Total iron binding capacity (TIBC).

i) Thyroid function tests.

j) Erythropoietin level.

These investigations were done as per standard protocols.

Statistical Methods: -Statistical analysis was done by using various statistical packages especially, SPSS 15.0, Minitab and web-based Java stat software. "p" value of $<0.05$ was taken as significant.

\section{Observations}

This study was conducted on 200 consecutive patients (both in patients and outpatients).

The demographic and clinical characteristics of the study patients are detailed in the Tables 1-6.

\section{Discussion}

A total of 200 consecutive patients (119 males and 81 females) with COPD documented by lung function tests, were evaluated for frequency of anemia. A total of 36 cases of anemia were detected.

The studied patients had a mean (SD) age of 61.4 (8.8) years with 62.3 (8.0) in males and 60.0 (9.7) in females. This is comparable to mean (SD) age 61 (1) years of subjects studied by Matthias John in 2005 [9].

In our study $59.5 \%$ of patients were males where as females constituted $40.5 \%$ of subjects. In the study by Matthias John, males constituted 65\% of patients which is comparable to our study. Anemic patients were sig- 
Table 1. Age and gender distribution of COPD patients.

\begin{tabular}{|c|c|c|c|c|}
\hline Age (yr) & Male $(n=119)$ & Female $(\mathrm{n}=81)$ & Total $(n=200)$ & Results \\
\hline Mean age (SD) & $62.3(8.0)$ & $60.0(9.7)$ & $61.4(8.8)$ & $\mathrm{p}>0.05$ (NS) \\
\hline 40 to 49 & $2(1.6 \%)$ & 10 (12.3\%) & 12 (6.0\%) & \multirow{4}{*}{$\mathrm{p}>0.05$ (NS) } \\
\hline 50 to 59 & 29 (24.37\%) & 16 (19.7\%) & 45 (22.5\%) & \\
\hline 60 to 69 & 62 (52.10\%) & $41(50.6 \%)$ & 103 (51.5\%) & \\
\hline$\geq 70$ & 26 (21.85\%) & $14(17.2 \%)$ & $40(20.0 \%)$ & \\
\hline
\end{tabular}

Table 2. Hemoglobin level in the studied patients.

\begin{tabular}{cccccccc}
\hline \multicolumn{2}{c}{ Parameter } & $\mathrm{n}$ & Minimum & Maximum & Mean & Std. Deviation & Results \\
\hline \multirow{3}{*}{ Anemia } & Present & 36 & 6.80 & 12.5 & 10.56 & 1.23 & $\mathrm{p}=0.000$ (Sig) \\
& Absent & 164 & 12.00 & 18.8 & 14.66 & 1.42 & \\
\multirow{3}{*}{ Gender } & Male & 119 & 6.80 & 18.8 & 14.28 & 2.07 & $\mathrm{p}=0.002(\mathrm{Sig})$ \\
& Female & 81 & 7.10 & 18.1 & 13.36 & 2.02 & 2.09 \\
\hline
\end{tabular}

Table 3. Type of anemia in the studied COPD patients.

\begin{tabular}{ccccc}
\hline PBF (type of anemia) & Male $(\mathrm{n}=20)$ & Female $(\mathrm{n}=16)$ & Total $(\mathrm{n}=36)$ & Results \\
\hline Normocytic normochromic & $18(90.0 \%)$ & $14(87.5 \%)$ & $32(88.8 \%)$ & \\
Normocytic hypochromic & $2(10.0 \%)$ & $2(12.5 \%)$ & $4(11.1 \%)$ & $\mathrm{p}=0.819$ (NS) \\
Total & $20(55.6 \%)$ & $16(44.4 \%)$ & $36(100.0 \%)$ & \\
\hline
\end{tabular}

Table 4. Iron profile in the anemic patients $(n=36)$.

\begin{tabular}{|c|c|c|c|c|c|}
\hline & rofile & Male $(n=20)$ & Female $(n=16)$ & Total $(n=36)$ & $\mathrm{p}$ value \\
\hline \multirow{2}{*}{ Serum iron $(\mu \mathrm{g} / \mathrm{dl})$} & Decreased $(<59)$ & $16(80.0 \%)$ & $11(68.7 \%)$ & 27 (75.0\%) & \multirow{2}{*}{0.582 (NS } \\
\hline & Normal (59 to 158 ) & $4(20.0 \%)$ & $5(31.2 \%)$ & $9(25.0 \%)$ & \\
\hline \multirow{2}{*}{ Saturation (\%) } & Decreased $(<16)$ & $10(50.0 \%)$ & $8(50.0 \%)$ & 18 (50.0\%) & \multirow{2}{*}{1.000 (NS } \\
\hline & Normal (16 to 50$)$ & $10(50.0 \%)$ & $8(50.0 \%)$ & $18(50.0 \%)$ & \\
\hline \multirow{2}{*}{ TIBC $(\mu \mathrm{g} / \mathrm{dl})$} & Decreased $(<259)$ & $16(80.0 \%)$ & $15(93.7 \%)$ & 31 (86.1\%) & \multirow{2}{*}{0.498 (NS) } \\
\hline & Normal (259 to 388) & $4(20.0 \%)$ & $1(6.2 \%)$ & $5(13.8 \%)$ & \\
\hline
\end{tabular}

nificantly older than non-anemic patients; mean(SD) age was 64.47 (7.97) and 60.71 ( 8.85 ) years in anemic and non-anemic patients respectively in our study whereas it was 72.8 (9.3) and 69.5 (8.8) years in anemic and non-anemic patients respectively in study by C. Cote which is comparable with our study [10].

The patients studied in our population were selected on the basis of GOLD criteria with FEV1/FVC ratio of less than 70\%; others have also used similar criteria (FEV1/FVC of $<70 \%$ ) in the selection of patients.

Smokers constituted $60 \%$ of the studied patients; Smokers constituted $95 \%$ of patients in the study by Matthias John. More than 50\% of smoker in our study were consuming 11 - 20 pack years of smoking which is lower than the smoking burden reported in the studies by C. Cote. This could be explained on the basis of lower smoking habits of our society.

In our study a significant proportion (58.3\%) of anemic COPD patients were non-smoker whereas in studies by C. Cote, there was no significant difference in smoking habits between anemic and non-anemic patients. This 
Table 5. Clinical profile and morbidity associated with the COPD patients under study.

\begin{tabular}{|c|c|c|c|c|c|}
\hline \multicolumn{2}{|l|}{ Parameter } & Anemic $(\mathrm{n}=36)$ & Non anemic $(n=164)$ & Total $(n=200)$ & $\mathrm{p}$ value \\
\hline \multicolumn{2}{|l|}{ Cough } & $36(100.0 \%)$ & $164(100.0 \%)$ & $200(100.0 \%)$ & 1.000 (NS) \\
\hline \multicolumn{2}{|l|}{ Expectoration } & 35 (97.2\%) & 159 (96.9\%) & $194(97.0 \%)$ & 0.931 (NS) \\
\hline \multicolumn{2}{|l|}{ Breathlessness } & 35 (97.2\%) & $149(90.8 \%)$ & $184(92.0 \%)$ & 0.203 (NS) \\
\hline \multirow{2}{*}{$\begin{array}{c}\text { Duration of } \\
\text { breathlessness (yrs) }\end{array}$} & $\leq 5$ & $11(30.5 \%)$ & $67(40.8 \%)$ & 78 (39.0\%) & \multirow{2}{*}{0.253 (NS) } \\
\hline & $>5$ & 25 (69.4\%) & 97 (59.1\%) & $122(61.0 \%)$ & \\
\hline \multirow[t]{2}{*}{ No. of exacerbations } & $\leq 5$ & 23 (63.8\%) & 139 (84.7\%) & $162(81.0 \%)$ & \multirow[t]{2}{*}{0.004 (Sig.) } \\
\hline & $>5$ & 13 (36.1\%) & 25 (15.2\%) & 38 (19.0\%) & \\
\hline \multirow{2}{*}{$\begin{array}{l}\text { No of hospital } \\
\text { admissions }\end{array}$} & $\leq 2$ & 15 (41.6\%) & $116(70.7 \%)$ & 131 (65.5\%) & \multirow{2}{*}{0.001 (Sig.) } \\
\hline & $>2$ & $21(58.3 \%)$ & $48(29.2 \%)$ & 69 (34.5\%) & \\
\hline \multicolumn{2}{|l|}{ Anorexia } & $17(47.2 \%)$ & 68 (41.4\%) & 85 (42.5\%) & 0.528 (NS) \\
\hline \multicolumn{2}{|l|}{ Weight loss } & $16(44.4 \%)$ & 50 (30.4\%) & $66(33.0 \%)$ & 0.108 (NS) \\
\hline \multicolumn{2}{|l|}{ Mean BMI } & $19.89(2.74)$ & $20.94(2.22)$ & $20.75(2.35)$ & 0.014 (Sig) \\
\hline
\end{tabular}

Table 6. Lung function in the studied patients.

\begin{tabular}{|c|c|c|c|c|c|}
\hline \multicolumn{2}{|c|}{ Lung functions } & \multirow{2}{*}{$\begin{array}{c}\text { Anemic }(n=36) \\
12(33.3 \%)\end{array}$} & \multirow{2}{*}{$\begin{array}{c}\text { Non anemic }(n=164) \\
52(31.7 \%)\end{array}$} & \multirow{2}{*}{$\begin{array}{c}\text { Total }(n=200) \\
64(32.0 \%)\end{array}$} & \multirow{2}{*}{$\begin{array}{c}\text { Result } \\
\mathrm{p}=0.850(\mathrm{NS})\end{array}$} \\
\hline FEV1/FVC (\%) & $<50$ & & & & \\
\hline FEV1\% of predicted & $<40$ & $3(8.3 \%)$ & $24(14.6 \%)$ & 27 (13.5\%) & $\mathrm{p}=0.318(\mathrm{NS})$ \\
\hline Mean FEV1\% o & & $53.36+13.12$ & $51.89+12.14$ & $52.15 \pm 12.22$ & $\mathrm{p}=0.515(\mathrm{NS})$ \\
\hline
\end{tabular}

again could be explained on the basis of lower smoking habits of our society especially females. There was no positive co-relation between smoking status and anemia in our studied patients which is similar to the studies by C. Cote.

Mean (SD) FEV1\% of predicted in our studied patients was 53.36 (13.12) in anemic patients while it was 51.89 (12.14) in non-anemic patients. In study conducted by Marya Zilberberg [13] it was 43.17 (16.95) and 42.07 (17.26) in anemic and non anemic patients respectively which is lower than in our patients.

Most of our studied patients were in GOLD Stage II where as majority of patients were in GOLD Stage III in another study by Matthias John. There was no co-relation between lung function tests and anemia. Similar results have been shown in the studies conducted by Matthias John, C. Cote, Marya Zilberberg [13] and Gokul Krishnan [14].

Mean hemoglobin (Hb) level in studied patients was 10.5 (1.23) g/dl and 14.66 (1.42) g/dl in anemic and non-anemic patients respectively which is consistent with another study by Matthias John with mean $\mathrm{Hb}$ of 11.9 (0.4) g/dl and 14.7 (0.2) g/dl in anemic and non-anemic patients respectively. In the study by C. Cote, mean Hb level was 11.8 (1.0) g/dl and 15.0 (1.2) g/dl in anemic and non-anemic patients respectively.

The frequency of anemia in our study was $18 \%$ which is similar to the frequency of $17 \%$ reported by C-Cote, 21\% by Michael Halpern [15] and 23\% by John Matthias [16]. There was no significant difference in frequency of anemia with respect to gender consistent with other studies by C. Cote, M.B. Stanbrook and Gokul Krishnan.

The frequency of anemia as per the criteria we have taken in our study ( $\mathrm{Hb}<13.5 \mathrm{~g} / \mathrm{dl}$ in males and $<12 \mathrm{~g} / \mathrm{dl}$ in females respectively), as was the criteria taken by the study on frequency of anemia in patients of COPD by Matthias John in 2005, was same as per WHO definition of anemia ( $\mathrm{Hb}<13 \mathrm{~g} / \mathrm{dl}$ in males and $<12 \mathrm{~g} / \mathrm{dl}$ in females respectively) [17], as there was no male patient with Hb level between 13 - $13.5 \mathrm{~g} / \mathrm{dl}$ in our study.

The frequency of polycythemia ( $\mathrm{Hb} \geq 17 \mathrm{~g} / \mathrm{dl}$ in males and $\geq 15 \mathrm{~g} / \mathrm{dl}$ in females respectively) was $11 \%$, which is higher than that (6\%) in the study by C. Cote. This could be explained by different sample size, and high alti- 
tude and relative hypoxemia in our population.

Out of 36 anemic patients, 32 (88.89\%) patients had normocytic normochromic type of anemia whereas 4 had normocytic hypochromic type of anemia.

Iron profile of the studied patients revealed that serum iron levels were decreased in three fourths of anemic patients, transferrin saturation was decreased in half of patients and total iron binding capacity (TIBC) was decreased in $86.11 \%$ of anemic patients. There was no difference in Iron profile between male and female patients. Although no study on iron profile in anemic COPD patients was available for comparison, the results are consistent with iron profile in anemia of chronic diseases in studies by Robert T. Means and LT Bart.

Erythropoietin levels were significantly raised in anemic patients 88.32 (55.94) $\mathrm{mIU} / \mathrm{ml}$ compared to non anemic patients 36.44 (30.32) $\mathrm{mIU} / \mathrm{ml}$. Similar results have been shown by another study by Matthias John.

The clinical parameters which had significant co-relation with anemia in our study were number of exacerbations of COPD and number of hospital admissions. Similar results have been seen in the studies conducted by Arnaud Chambellan [18].

Anorexia and weight loss were present in more than $1 / 3$ of the studied patients. Compared to nonanemic patients, COPD patients with anemia did not show decreased appetite or weight loss. Similar results have been seen in the study conducted by Matthias John.

Mean (SD) body mass index of our study population was $19.89(2.74) \mathrm{kg} / \mathrm{m}^{2}$ in anemic and 20.94 (2.22) $\mathrm{Kg} / \mathrm{m}^{2}$ in non-anemic patients, where as it was $23.8(1.7)$ and $23.2(0.6) \mathrm{kg} / \mathrm{m}^{2}$ respectively in anemic and nonanemic patients in Matthias John's study.

This could be explained on the basis of geographical and socio-economic status difference between two populations. Body mass index was positively co-related with hemoglobin consistent with another study by Arnaud Chambellan.

\section{Summary and Conclusions}

- Two hundred patients (119 males and 81 females) with a mean (SD) age of 61.4 (8.8) years having COPD diagnosed by GOLD criteria were evaluated for frequency of anemia. In addition to baseline investigations, erythropoietin levels were done in a subgroup of studied patients.

- A total of 36 cases of anemia were detected giving a frequency of $18 \%$. Twenty of these anemic patients were males and 16 were females. Normocytic normochromic type of anemia was present in 32 (88.89\%) patients while the rest had normocytic hypochromic type of anemia. The patients with anemia were mostly nonsmokers. Majority of patients were in GOLD Stage II with a mean FEV1 of 53.36 (13.12) percent of the predicted in anemic COPD patients.

- Majority of anemic patients had decreased serum iron levels, transferrin saturation and TIBC.

- The various factors significantly associated with anemia in our study were number of exacerbations of COPD, number of hospital admissions, BMI and erythropoietin levels.

In conclusion, anemia occurs frequently in patients of COPD and is associated with increased morbidity in the form of number of exacerbations and hospital admissions. Correcting anemia in these patients may improve their clinical outcome.

\section{Limitations}

Our study being a hospital based study may not truly reflect the frequency of anemia in COPD patients in community at large.

\section{References}

[1] Weiss, G. and Goodnough, L.T. (2005) Anemia of Chronic Disease. New England Journal of Medicine, 352, 1011. http://dx.doi.org/10.1056/NEJMra041809

[2] Means Jr., R.T. (2003) Recent Developments in Anemia of Chronic Disease. Current Hematology Reports, 2, 116121.

[3] Ezekowitz, J.A., MCA Lister, F.A. and Armstrong, P.W. (2003) Anemia Is Common in Heart Failure and Is Associated with Poor Outcomes: Insights from a Cohort of 12065 Patients with New-Onset Heart Failure. Circulation, 107, 223-225. http://dx.doi.org/10.1161/01.CIR.0000052622.51963.FC

[4] Augusti, A.G., Noguera, A., Sauleda, J., Sala, E., Pons, J. and Busquets, X. (2003) Systemic Effects of Chronic Ob- 
structive Pulmonary Disease. European Respiratory Journal, 21, 347-360. http://dx.doi.org/10.1183/09031936.03.00405703

[5] Means Jr., R.T. (1999) Advances in the Anemia of Chronic Disease. International Journal of Hematology, 70, 7-12.

[6] Paul, R.A., et al. (2001) Global Strategy for Diagnosis Management and Prevention of Chronic Obstructive Pulmonary Disease NHLB1/WHO Obstructive Lung Disease (GOLD) Workshop Summary. American Journal of Respiratory and Critical Care Medicine, 46, 798-825.

[7] Pruitt, B. (2007) COPD: New Guidelines from the 2006 GOLD Report.

[8] Schols, A.M. (2002) Pulmonary Cachexia. International Journal of Cardiology, 85, 101-110. http://dx.doi.org/10.1016/S0167-5273(02)00238-3

[9] John, M., Hoernig, S., Doehner, W., Okonko, D., Witt, C. and Danker, S. (2005) Anemia and Inflammation in COPD. Chest, 127, 825-829. http://dx.doi.org/10.1378/chest.127.3.825

[10] Cote, C., Zilberberg, M.D., Mody, S.H., Dordelly, L.J. and Celli, B. (2007) Haemoglobin Level and Its Clinical Impact in a Cohort of Patients with COPD. European Respiratory Journal, 29, 923-929. http://dx.doi.org/10.1183/09031936.00137106

[11] Similowski, T., Augusti, A., Mac Née, W. and Schonhofer, B. (2006) The Potential Impact of Anemia of Chronic Disease in COPD. European Respiratory Journal, 27, 390-396. http://dx.doi.org/10.1183/09031936.06.00143704

[12] Schonhofer, B., Wenzel, M., Geibel, M. and Kohler, D. (1998) Blood Transfusion and Lung Function in Chronically Anemic Patients with Severe Chronic Obstructive Pulmonary Disease. Critical Care Medicine, 26, 1824-1828. http://dx.doi.org/10.1097/00003246-199811000-00022

[13] Zilberberg, M., Cote, C., Mody, S.H., Pharm, D. and Celli, B. (2005) Anemia in Chronic Obstructive Pulmonary Disease (COPD): Association with Supplemental $\mathrm{O}_{2}$ Use and Hospitalizations. American College of Physicians. Chest, 128.

[14] Krishnan, G., Grant, B.J., Muti, P.C., Mishra, A., Ochs-Balcom, H.M., Freudenheim, J.L., Trevisan, M. and Schunemann, M. (2006) Association between Anemia and Quality of Life in a Population Sample of Individuals with Chronic Obstructive Pulmonary Disease. BCM Pulmonary Medicine, 6, 23. http://dx.doi.org/10.1186/1471-2466-6-23

[15] Carroz, K.P. (2007) Anemia in COPD: Should It Be Taken into Consideration? Archivos de Bronconeumología, 43, 392-398. http://dx.doi.org/10.1016/S1579-2129(07)60091-3

[16] Ortakoylu, G., Bahadir, A., Alkan, F. and Caglar, E. (2006) Respiratory Medicine, Yedikule Chest Hospital Istanbul, Turkey. Prevalence of Anemia in Patients with COPD. Oral Presentation.

[17] Pinto-Plata, V.M., Cote, C., Cabral, H., Taylor, J. and Celli, B.R. (2004) The 6-min Walk Distance: Change over Time and Value as a Predictor of Survival in Severe COPD. European Respiratory Journal, 23, 28-33. http://dx.doi.org/10.1183/09031936.03.00034603

[18] Park, M.M., Durrani, J. and Zilberberg, M. (2003) Co-Relation of Severity of Anemia with Severity of COPD. American Journal of Respiratory and Critical Care Medicine, 167, A234. 